University of Nebraska - Lincoln

DigitalCommons@University of Nebraska - Lincoln

Faculty Publications, Department of Psychology

Psychology, Department of

March 1991

\title{
The Altruistic Personality: In What Contexts Is It Apparent?
}

\author{
Gustavo Carlo \\ University of Nebraska-Lincoln, carlog@missouri.edu \\ Nancy Eisenberg \\ Arizona State University, nancy.eisenberg@asu.edu \\ Debra Troyer \\ Arizona State University \\ Galen Switzer \\ Arizona State University \\ Anna L. Speer \\ Arizona State University
}

Follow this and additional works at: https://digitalcommons.unl.edu/psychfacpub

Part of the Psychiatry and Psychology Commons

Carlo, Gustavo; Eisenberg, Nancy; Troyer, Debra ; Switzer, Galen; and Speer, Anna L., "The Altruistic Personality: In What Contexts Is It Apparent?" (1991). Faculty Publications, Department of Psychology. 192.

https://digitalcommons.unl.edu/psychfacpub/192

This Article is brought to you for free and open access by the Psychology, Department of at DigitalCommons@University of Nebraska - Lincoln. It has been accepted for inclusion in Faculty Publications, Department of Psychology by an authorized administrator of DigitalCommons@University of Nebraska - Lincoln. 
Published in Journal of Personality and Social Psychology 61:3 (1991), pp. 450-458. Copyright (C) 1991 by the American Psychological Association. Inc. Used by permission. http://www.apa.org/journals/psp/ "This article may not exactly replicate the final version published in the APA journal. It is not the copy of record."

\title{
The Altruistic Personality: In What Contexts Is It Apparent?
}

\author{
Gustavo Carlo, Nancy Eisenberg, Debra Troyer, Galen Switzer, and Anna L. Speer \\ Arizona State University
}

\begin{abstract}
Hypotheses concerning the specific contexts in which an altruistic personality might be most apparent were investigated, College students completed questionnaires tapping components of an altruistic personality, emotionality, and social desirability. At a 2nd session, the emotional evocativeness and ease of escape from the helping situation were experimentally manipulated. Ss were exposed to a distressed woman, completed state sympathy and personal distress indexes, and were given an opportunity to assist the woman. High scorers on dispositional altruism were expected to assist most when escape was easy, particularly when the distress cues were obvious. Altruistic and emotionally reactive persons were also expected to help most in a psychologically "weak" environment. Both predictions were supported. The relations between helping and the other predictors were also examined.
\end{abstract}

In recent years, there has been considerable debate concerning whether or not there is an altruistic personality (Batson, Bolen, Cross, \& Neuringer-Benefiel, 1986; Rushton, 1980). Included among personality variables relevant to the notion of an altruistic disposition are other-oriented cognitive and affective tendencies such as sympathy (i.e., other-oriented concern or sorrow for another), social responsibility, ascription of responsibility, and perspective taking (i.e., understanding another's cognitive point of view or affective situation; Batson et al., 1986; Schwartz \& Howard, 1984; Staub, 1974). ${ }^{1}$

Few researchers would now argue that persons with an altruistic personality are more prosocial in all contexts. Rather, consistent with the prevailing contemporary perspectives on personality (Romer, Gruder, \& Lizzadro, 1986; Snyder \& Ickes, 1985), those who support the notion of an altruistic personality have suggested that there is a person-situation interaction in regard to altruistic tendencies. However, there has not been consensus in regard to the situations in which altruistic tendencies are evident.

One prediction stems from the work of Batson and his colleagues. Batson (1987) has primarily examined contexts in which it is possible to differentiate situationally produced sympathy from situational personal distress (i.e., a self-focused, aversive reaction to others' cues of distress; also see Davis, 1983). He has argued that sympathetic responses are likely to lead to altruistically motivated helping responses, whereas personal distress mayor may not lead to an egoistically motivated helping response. Specifically, when escape from the distressful situation is diffi-

The research was supported by National Science Foundation Minority Graduate Student Grant BNS-8917866 to Gustavo Carlo and Nancy Eisenberg and by National Science Foundation Grant BNS8807784 and Institute of Child Health and Development Grant K04HDO00717 to Nancy Eisenberg. We gratefully acknowledge the assistance of Robert Cialdini, Frank Cordova, Carla German, Beth Green, Kirk Guinn, and Mark Schaller and the statistical advice of Sandy Braver and George Knight.

Galen Switzer is now [1991] at the Department of Sociology, University of Colorado at Boulder. cult (e.g., when one cannot avoid the emotion-eliciting situation), a person experiencing personal distress may help the needy other primarily to alleviate his or her own vicariously induced distress. However, when escape is easy (e.g., when one can leave the situation with minimal or no self-imposed or other-imposed consequences), people experiencing personal distress frequently avoid the situation to alleviate their own distress, whereas individuals experiencing sympathy are likely to assist.

Although not all researchers agree with Batson's arguments regarding the existence of true altruism and the circumstances in which it is elicited (e.g., Cialdini et al., 1987), there is considerable evidence for an association between situational sympathy and prosocial behavior (see Batson, 1987; Eisenberg, Fabes, et al., 1989; Eisenberg, Miller, et al., 1989; Schroeder, Dovidio, Sibicky, Matthews, \& Allen, 1988). However, Batson's notions regarding the conditions in which one can differentiate between altruistic (i.e., sympathetically motivated) behavior and nonaltruistic helping have seldom been examined in regard to dispositional tendencies (cf. Romer et al., 1986).

In one of the few relevant studies, Batson et al. (1986) found some altruistic personality measures were positively related to helping when escape was difficult, but the correlations were nonsignificant when escape was easy. Batson et al. argued that one would expect a positive relation between the dispositional indexes of altruism and helping when escape from the emotional stimulus was easy if the helpers were truly altruistic; the correlations between dispositional indexes of altruism and helping in the difficult escape context were viewed as indicating that helpers were

\footnotetext{
${ }^{1}$ There is much current debate concerning the definition of altruism. In the present study, the definition of altruism used was based on the work of previous researchers (e.g., Eisenberg, 1986; Rushton, 1980; Staub, 1974). Specifically, altruism is defined as voluntary behavior not motivated by the expectation of external rewards or by the avoidance of aversive external stimuli. Included in this definition of altruism is prosocial behavior motivated by the desire to adhere to internalized principles (the absence of which may be associated with self-condemnation).
} 
concerned about their self-image. In a similar study, Eisenberg, Miller, et al. (1989) found some significant positive relations between dispositional altruistic measures (dispositional sympathy; perspective taking, and ascription of responsibility) and helping. Although ease of escape was not manipulated in their study, they considered their helping context to be easy to escape. Thus, at this time, there are conflicting data regarding the existence of an altruistic personality.

To reiterate, on the basis of Batson's (1987) theorizing and findings regarding easy-escape versus difficult-escape situations, if there is an altruistic personality; one would expect to find an association between altruistic personality traits and helping in an easy-escape context. In addition, Eisenberg (1986) has suggested that sympathetic, altruistically motivated individuals might be expected to help more than other persons only if the potential recipient appears to be needy or distressed. If the potential recipient of help does not evoke sympathy and does not appear to be needy, there is little reason to expect altruistic people to assist more than other individuals. Thus, on the basis of Batson's and Eisenberg's arguments, one would predict that altruistic persons would be most discernible in easy-escape contexts (Batson, 1987), particularly when the other's need is relatively obvious (Eisenberg, 1986).

Snyder and Ickes (1985) have suggested an alternative hypothesis regarding when dispositions are most likely to be manifest. Specifically, they have argued that the strength of relation between personality variables and behavior varies as a function of the strength of situational "pulls" for behavior in a given experimental context. In a "strong" environment, the situational factors (e.g., experimental manipulations or situational demands) that influence behavior are so strong that the influence of an individual's dispositional tendencies is limited and may be overridden by the salient situational factors. In contrast, in a "weak" environment (i.e., in a nonmanipulated situation or in an environment with less demand characteristics), the individual's natural response tendencies are relatively free to be expressed. Thus, measures of dispositions are relatively less likely to be significantly related to social behavior in an experimental context involving a strong relevant manipulation than in one involving a weaker manipulation.

\section{The Present Study}

To examine the relations of trait and state indexes to helping, we manipulated the emotional evocativeness of a potential recipient of help and the ease with which subjects could escape from cues pertaining to the potential recipient's need (a $2 \times 2$ design). With this design, we examined the two aforementioned hypotheses regarding the relations of dispositional indexes of sympathy and personal distress to helping. In this study, we considered the situation in which the other person's distress was mild and easy to escape as the "weakest" situation, and the context in which the other's distress was more evident and escape was difficult as the "strongest."

In addition, we examined whether the relation between general emotional reactivity and helping would vary in accordance with Snyder and Ickes's notions regarding weak and strong situations. Because emotionally reactive persons would be expected to experience relatively high levels of both sympathy and personal distress in an emotionally evocative situation (Eisenberg et al.,
1991; Mehrabian, 1980), we expected dispositional emotional reactivity to be unrelated to helping in a highly evocative, easy-escape context. In contrast, dispositional emotional reactivity was expected to be positively related to helping in a low-evocative, easy-escape context (i.e., a "weak" situational context). This latter prediction was based not only on Snyder and Ickes' predictions, but also on the assumption that dispositionally reactive persons, rather than less reactive persons, would be more likely to respond sympathetically to a mildly distressed other (Larsen \& Diener, 1987) and would also be unlikely to become overly aroused and experience personal distress (see Eisenberg, Bernzweig, \& Fabes, in press; Hoffman, 1982).

Finally, we examined the relation of dispositional social desirability to helping. Social desirability concerns have been associated with self-reported situational vicarious emotional responding (i.e., self-reports of emotional responses in the given context; Cialdini et al., 1987; Eisenberg, Miller, et al., 1989) and have been viewed as influencing helping behavior in some studies concerning the relation of sympathy to prosocial behavior (e.g., Archer, 1984; Cialdini et al., 1987). However, to our knowledge, no one has systematically examined the types of contexts in which concern with social desirability is most likely to influence helping behavior. Because we were uncertain whether people would feel pressure to act in a socially desirable manner when confronted with clear cues of distress or when in a psychologically "weak" context, we made no a priori predictions regarding the relation of social desirability to helping.

\section{Method}

\section{Subjects}

Participants were 134 undergraduate college students ( $M$ age $=20.16$ years, $S D=3.39$, range $=17-35$ ) who received credit for an introductory psychology course. We dropped 22 subjects $(16 \%)$ because they were deemed highly suspicious during debriefing; 1 subject was also dropped because of equipment problems, and 2 were dropped because they did not complete both sessions of the study. Of the subjects dropped because of suspicion, there were 13 women ( 5 in each of the low-evocative conditions, 2 in the high-evocative, difficult-escape condition, and 1 in the high-evocative, easy-escape condition) and 9 men ( 2 in each of the low-evocative conditions, 1 in the high-evocative, difficultescape condition, and 4 in the high-evocative, easy-escape condition). ${ }^{2}$ Thus, 109 subjects were randomly assigned to four conditions: low-evocative, easy-escape (11 men and 13 women); lowevocative, difficult-escape (12 men and 15 women); high-evocative, easy-escape (11 men and 17 women); and high-evocative, difficult-escape (13 men and 17 women). In addition, 5 subjects left numerous items blank on some of the questionnaires, resulting in their being dropped in some analyses.

\footnotetext{
${ }^{2}$ The high rate of suspicion may have been due to the fact that the study was conducted well into the second semester (when subjects may have heard about studies involving deception). Nonetheless, the rate of suspicion for this study (16\%) is comparable to other analogous studies (e.g., 18\% in Batson et al., 1986).
} 


\section{Materials and Procedure}

We selected the personality measures for the present study on the basis of previous research (Batson et al., 1986; Eisenberg, Miller, et al., 1989; Staub, 1974). Furthermore, in order to compare the results of our present study with those of other researchers, we included state measures of vicarious emotional responding similar to those used in other related studies (Batson, 1987; Eisenberg, Miller, et al., 1989; Fultz, Schaller, \& Cialdini, 1988).

Subjects were recruited in groups for a study purportedly on impression formation. When they arrived at the experimental room, subjects were told that the equipment necessary for the study was not ready, but that they could participate in a different study concerning personality traits and schedule another day for the impression formation study. Then all subjects were administered a battery of trait measures in counterbalanced order that included the following: ascription of responsibility (Schwartz, 1968; $\alpha=.84$ ), social responsibility (Berkowitz \& Lutterman, 1968; $\alpha=.55$ ), ${ }^{3}$ social desirability (Crowne \& Marlowe, 1964; $\alpha=.75$ ), affective intensity (Larsen $\&$ Diener, 1987; $\alpha=.89$ ), and empathy (Davis, 1983). Three of four of the subscales from the Davis empathy measure were administered: empathic concern (i.e., sympathy; $\alpha=.67$ ), perspective taking $(\alpha=.75)$, and personal distress $(\alpha=.78)$.

At the second session, subjects were counterbalanced (within gender) across the four conditions. When a subject arrived for the second session (1-2 weeks after the first session), he or she was brought into a room containing a chair facing a video color monitor. The experimenter and the room were different from those in the first session.

The subject was told that he or she had been randomly assigned to the observer's role, which involved performing an impression formation task. Subjects were instructed, "Your job will be to fill out some questionnaires on your impression of Beth [the confederate worker]. We want to find out how people form first impressions of people who are engaged in a task." Subjects were told that another experimenter (Mark) was in charge of the study, that Mark was going to interview the worker, and that the worker did not know he or she was being evaluated. Actually, the worker (a young woman) and Mark were confederates prerecorded on videotape. Subjects were told that the worker's task was to read some brief descriptions about an assault written by journalism students for a class, and that these assignments were supposed to be detailed and impactful. In addition, subjects were told that at various times Mark would ask the subject, over a one-way intercom (purportedly so that Mark would not influence the subject's answers), to fill out some questionnaires. Subjects also were told that there were going to be some questions about feelings and emotions because the way someone feels can influence how they evaluate others.

Next, to increase the credibility of the study, subjects were administered a short questionnaire concerning any journalism-related experiences or courses they had taken previously. During this time, the experimenter left the room, purportedly to check whether the worker had arrived and was ready to start. After about $60 \mathrm{~s}$, the experimenter returned, said they were ready to start, and turned on the television monitor. The experimenter then left, and $20 \mathrm{~s}$ later turned on the videotape from an adjoining room.

Subjects watched Mark introduce himself to the worker and explain the general procedure to her on the color monitor. The worker agreed to read all of the 15 descriptions of assaults. The confederates then proceeded to the task: The worker silently read a brief description and then Mark asked the worker a series of four questions (pertaining to writing style, quality, and subjective preference) for each description. During the first assault description, the worker showed no visible signs of distress and answered the questions in a casual manner. After the first description, Mark gave the worker a questionnaire to complete and excused himself from the room to check on something. This segment of the videotape was the same in all conditions.
At this point, the subject's video monitor screen went blank and Mark's voice came over the intercom. Mark asked the subject to complete an adjective rating scale (7-point items ranging from not at all to extremely) that tapped mood (the items were "happy," "low-spirited," "anxious," "feeling good," "sad," "agitated," "elated," and "feeling low"). Then Mark informed the subject that he was going to return to the worker.

The subject's monitor showed Mark returning and then administering the second assault description. At this point, the worker began to show visible, mild signs of agitation and distress (her brow creased and she shifted in her seat); by the second question the worker showed an increase in agitation (tapped a pencil, shifted in her seat, rubbed her hands together, avoided eye contact, and answered with hesitation), although her level of overall distress was still low.

From this point on, the interaction between Mark and Beth reviewed by the subjects and the instructions over the intercom were modified to reflect the condition to which the subject had been assigned. In the high-evocative conditions, by the third and fourth questions, the worker showed significant signs of distress and agitation (i.e., was visibly emotional and choking back tears); cues of emotional distress were relatively subtle in the low-evocative condition. Ratings of the emotional evocativeness of each of the two videotapes by a different group of undergraduate and graduate students (five male and five female raters for each videotape) indicated that the high-evocative videotape was more emotionally evoking than the low-evocative videotape, $t(18)=5.42, p<.001$. In all conditions, the worker hesitantly confessed that she had been assaulted a few months before and that the procedure was bringing back some bad memories. When asked if she wished to continue, she expressed a desire to do so because of her commitment to finishing the study. Mark, looking concerned, suggested that she take a break and then left the room.

At this point, the subject's monitor went blank for 2 min while Mark talked to the subject over the intercom. Mark instructed the subject to complete the second adjective questionnaire that tapped sympathy (the items were "sympathetic," "touched," "soft-hearted," "sorrowful," "compassionate," and "concerned about others") and personal distress (the items were "distressed about self," "disturbed," "troubled," "uneasy," and "alarmed"). Then, after stating that he had not discussed the idea with the worker, he suggested that the subject might want to trade places with the worker because of the worker's difficulty completing the task. He assured the subject that there was no obligation to do so. The ease of escape manipulation was introduced at this point.

In the easy-escape conditions, subjects were told that if they did not want to trade tasks, they would not have to watch any of the worker's remaining descriptions. They would be required only to fill out a "number of questionnaires for the remainder of the hour and then you'll be free to go." In the difficult-escape conditions, subjects were told that they would have to continue to watch the worker's remaining 13 descriptions and that, " . . . after you've done that and completed the second reaction questionnaire, which will take the rest of the hour, then you'll be free to go."

Subjects in all conditions were told that trading places with the worker required the subject to schedule another session on another day without additional class credits; thus, helping was costly in terms of time (requiring subjects to return for a third session). Subjects could agree to take the worker's place for as many, or as few, of the remaining 13 descriptions as they wished. Then Mark informed the subject that he was going back to check on the worker and that the other experimenter (who had originally

\footnotetext{
${ }^{3}$ Because this scale is combined with other scales in most subsequent analyses, the relatively low alpha was not considered a substantial problem.

${ }^{4}$ Subjects also rated the worker on similarity to themselves. The similarity ratings were unrelated to any measures of interest.
} 
met the subject) would come to get his or her response. After $30 \mathrm{~s}$, the other experimenter walked in and asked for the response. If subjects agreed to help, they were asked how many descriptions they were willing to evaluate. At that time, the subjects were probed for suspicions and debriefed.

\section{Results}

The percentages of those who helped in each condition were as follows: $30 \%$ in the low-evocative, difficult-escape condition, $29 \%$ in the low-evocative, easy-escape condition, $53 \%$ in the high-evocative, difficult-escape condition, and 39\% in the highevocative, easy-escape condition. Helping scores ranged from 0 (no helping) to 13 (willing to do all the remaining descriptions). There was a bimodal distribution in helping scores on the continuous raw helping scores. Thus, an arcsine transformation was computed on the continuous raw helping scores (Kenny, 1987) and these transformed scores were used for all subsequent analyses.

\section{Initial Analyses}

We expected that helping would be highest in the high-evocative, difficult-escape condition because the other's need was more evident and people experiencing either sympathy or personal distress would be expected to assist. To assess the effect of the ease of escape and emotional evocativeness on helping, we conducted a 2 (Sex) $\times 2$ (Escape; easy-difficult) $\times 2$ (Evocativeness; high-low) analysis of variance with helping as the dependent variable. There was a significant main effect of evocativeness, $F(1,101)=4.38, p$ $<.05$. There was less helping in the low-evocative conditions than in the high-evocative conditions ( $M \mathrm{~s}=.37$, low-evocative, easyescape; .34, low-evocative, difficult-escape; .49, high-evocative, easy-escape; and .78, high-evocative, difficult-escape). Moreover, we conducted a $2(\mathrm{Sex}) \times 4$ (Condition) planned comparison with helping as the dependent variable, comparing the high-evocative, difficult-escape to the other three conditions. There was a significant main effect, of condition, $F(1,101)=5.95, p<.05$, indicating that there was more helping in the high-evocative, difficult-escape condition than in the other three conditions combined. ${ }^{5}$

\section{Interrelations Among the Trait and State Measures}

To assess the possibility of reducing the number of correlations and of computing composite indexes, we conducted a varimax factor analysis using the dispositional indexes of altruism and emotionality (perspective-taking, sympathy, personal distress, social responsibility, ascription of responsibility, and emotional intensity scores). Trait social desirability was not included in the factor analysis because it was not believed to reflect either an altruistic disposition or emotionality. A two-factor solution emerged when an eigenvalue of 1.0 was used (see Table 1). Indexes loading high (above .60) on the first factor (ascription of responsibility, perspective taking, social responsibility, and trait sympathy; $\alpha=.89$ ) seemed to reflect an altruistic disposition and accounted for $42 \%$ of the factor variance. Indexes loading high on the second factor (personal distress and emotional intensity; $\alpha=.90$ ) seemed to reflect emotionality and accounted for $22 \%$ of the factor variance. On the basis of the factor analysis, we constructed prosocial and emotionality composite indexes by standardizing and summing scores on the component indexes.

Table I

Varimax Rotated Factor Loadings Using Six Trait Measures

Trait measure

Ascription of responsibility

Perspective taking

Social responsibility

Sympathy

Emotional intensity

Personal distress

Note. Eigenvalues for each factor were $>1.0$. Factor 1 accounted for $41.8 \%$ of the factor variance and Factor 2 accounted for $21.7 \%$ of the factor variance. Variables with loadings greater than .60 were used for interpretation.

A similar factor analysis was conducted with the adjectives used to assess state sympathy and state personal distress. Two distinguishable factors emerged (see Table 2). The sympathy and personal distress adjectives loaded on separate factors, accounting for $60 \%$ and $13 \%$ of the factor variance, respectively ( $\alpha \mathrm{s}=$ .94 and .89 , respectively). When both the aforementioned factor analyses were computed using both high- and low-suspicion subjects, the results were virtually identical. Thus, for most of the subsequent analyses, the variables used were the prosocial composite, the emotional arousability composite, social desirability, state sympathy; and state personal distress. The means and standard deviations for these measures in each of the evocativenessescape conditions are presented in Table 3.

The $t$-test analyses indicated that women scored higher than men on the dispositional prosocial and arousability composites (for the prosocial composite, $M$ for men $=-1.15, S D=2.79 ; M$ for women $=.92, S D=2.89$, and for the arousability composite, $M$ for men $=-.68, S D=1.46 ; M$ for women $=.53, S D=1.69$ ), $t(102)=3.65$ and $t(104)=3.84$, respectively, both $p \mathrm{~s}<.001$. Furthermore, social desirability scores were significantly related to scores on the prosocial composite, $r(102)=.36, p<.001$. Because sex and social desirability were related to at least one of the trait composite indexes, and the relations of social desirability to helping were expected to differ across conditions, we computed partial correlations controlling for sex and social desirability; in addition to the zero-order correlations in subsequent relevant analyses.

\section{Relations of Helping to State Indexes Within Condition}

To compare the present data to other similar studies involving state indexes of sympathy and personal distress, we computed partial correlations, controlling for both sex and social desirability .between the state measures and helping within each condition (see Table 4). As can be seen in the table, scores on the state sympathy measure were positively related to helping in the

\footnotetext{
${ }^{5}$ We performed $t$ tests to determine whether high-suspicion subjects differed from low-suspicion subjects on the trait and state scores. The only significant differences were for state sympathy and personal distress, $t \mathrm{~s}(129)=3.17$ and 2.96 , respectively, $p \mathrm{~s}<.005$. High-suspicion subjects scored lower on these indexes.
} 
Table 2

Varimax Rotated Factor Loadings Using the State Sympathy and Personal Distress Items

$\begin{array}{llc}\text { Item } & \text { Factor } 1 & \text { Factor } 2 \\ \text { Sympathetic } & .79 & .30 \\ \text { Touched } & \mathbf{. 8 4} & .24 \\ \text { Soft-hearted } & .79 & .19 \\ \text { Compassionate } & \mathbf{. 8 9} & .24 \\ \text { Sorrowful } & .75 & .36 \\ \text { Concern for others } & . \mathbf{8 6} & .31 \\ \text { Distressed about self } & .15 & . \mathbf{6 4} \\ \text { Disturbed } & .41 & . \mathbf{9 1} \\ \text { Troubled } & .47 & \mathbf{. 6 9} \\ \text { Uneasy } & .31 & \mathbf{. 8 3} \\ \text { Alarmed } & .15 & . \mathbf{7 9}\end{array}$

Note. Eigenvalues for each factor were $>1.0$. Factor 1 accounted for $59.9 \%$ of the factor variance and Factor 2 accounted for $13.4 \%$ of the factor variance. Variables with loadings greater than .60 (in boldface) were used for interpretation.

high-evocative, easy-escape condition, but not in the other three conditions. Furthermore, there were no significant relations between helping and state personal distress.

To assess differences across conditions in the relations of state sympathy to helping, we computed a regression analysis. In this analysis, social desirability and sex were entered first in a block; state sympathy and condition (a planned contrast that compared the high-evocative, easy-escape condition with the remaining three conditions) were entered next in a block; the Sex $\times$ Condition and the State Sympathy $\times$ Sex interactions were entered third; the State Sympathy $\times$ Condition interaction was entered fourth; and the three-way interaction was entered last. The second block of variables containing sympathy significantly predicted helping, $r^{2}$ change $=.06$ (over and above the contributions of sex and social desirability), $F(1,102)$ for $r^{2}$ change $=3.37, p<.05$ (multiple $R=.27) ; t(104)$ for sympathy $=2.58, p<.01$. State sympathy was positively related to helping across all conditions, partial $r(103)=$ $.24, p<.01$. The Sympathy $\times$ Condition interaction was a marginally significant predictor of helping, $r^{2}$ change $=.03, F(1,99)$ for $r^{2}$ change $=3.05, p<.08$ (multiple $R=.37$ ). Sympathy was positively related to helping in the high-evocative, easy-escape condition, partial $r(24)=.48, p<.01$, but was unrelated to helping in the other three conditions combined, partial $r(75)=.14$.

To assess differences across conditions in the relations of state personal distress to helping, we computed another regression analysis. In this analysis, sex and social desirability were entered first; state personal distress and condition were entered second; the Sex $\times$ State Personal Distress and the Sex $\times$ Condition interactions were entered third; the State Personal Distress $\times$ Condition interaction was entered fourth; and the three-way interaction was entered last. Personal distress was a marginally significant predictor of helping, $r^{2}$ change $=.05, F(1,102)$ for $r^{2}$ change $=$ $2.82, p<.06$ (multiple $R=.25$ ); $t(104)=1.94, p<.06$. State personal distress was marginally, positively related to helping across conditions, partial $r(103)=.19, p<.06$. There were no significant interaction effects. Moreover, the results were similar for a regression analysis comparing the relation of state personal distress to helping in the high-evocative, difficult-escape condition (where the correlation might be expected to be highest), with the relations in the other three conditions combined. The results of all the aforementioned analyses were also very similar when highsuspicion subjects were included in the computations. ${ }^{6}$

\section{Relations of Helping to Trait Indexes Within Condition}

To test the main hypotheses concerning the dispositional indexes, we computed partial correlations controlling for both sex and social desirability (for the prosocial composite) and controlling for sex only (for the emotional arousability composite) between helping and the trait composites within each condition. Consistent with Snyder and Ickes's (1985) predictions, the trait emotional arousability composite was positively related to helping in the low-evocative, easy-escape condition (see Table 4). In accordance with the above findings on the relation between state sympathy and helping and the argument that personal characteristics predict helping only when those characteristics are situationally relevant, the trait prosocial composite was positively related to helping in the high-evocative, easy-escape condition. Furthermore, high scores on social desirability were associated with more helping in the low-evocative, difficult-escape condition. ${ }^{7}$

To further test the various predictions stemming from discussions pertaining to an altruistic personality and Snyder and Ickes's (1985) theorizing, we performed a series of regression analyses. According to Eisenberg's (1986) notion that dispositional traits relate to helping only when they are relevant in the given situation and according to Batson's (1987) findings in regard to easy and difficult escape situations, dispositional altruism was expected to be most highly positively correlated to helping in the highevocative, easy-escape condition, and least related in the difficultescape conditions. Thus, in the first analysis, we compared the association of the prosocial composite to helping in the high-evocative, easy-escape condition with the relations in both the high-

\footnotetext{
${ }^{6}$ We also examined the relation of helping to state sadness, because researchers have argued that feelings of sadness may motivate helping in order to alleviate one's sadness (Cialdini et al., 1987) or because empathic sadness may turn into sympathy (Eisenberg, Fabes, et al., 1989). Subjects were administered adjectives related to sadness (feeling low, sad, heavy-hearted, and low-spirited; alpha $=.85$ ) before and after watching the evocativeness segment along with the other state indexes. Sadness was unrelated to helping in each of the conditions ( $r$ s ranged from -.08 to .30). Multiple regressions similar to those described for the other state variables were not significant.

${ }^{7} \mathrm{~F}$ tests revealed no significant differences in the variances of helping scores or in the means of the trait composite measures across conditions. Nonetheless, we examined the correlations in each condition, correcting for differences in the variances of helping (Cohen \& Cohen, 1983) by considering the standard deviation for the entire sample as an estimate of the standard deviation for helping in the population. The results of these analyses were very similar to those in Table 4, albeit slightly stronger in both low-evocative conditions and slightly weaker in both high-evocative conditions. Moreover, the correlations between the trait indexes and helping were very similar to those presented in Table 4 when they were computed using all subjects (including suspicious subjects).
} 
Table 3

Scores on the Trait and State Measures in Each of the Evocativeness-Escape Conditions

\begin{tabular}{|c|c|c|c|c|c|c|c|c|}
\hline \multirow[b]{2}{*}{ Measure } & \multicolumn{2}{|c|}{$\begin{array}{l}\text { Low-difficult } \\
\quad(n=27)\end{array}$} & \multicolumn{2}{|c|}{$\begin{array}{l}\text { Low-easy } \\
(n=24)\end{array}$} & \multicolumn{2}{|c|}{$\begin{array}{l}\text { High-difficult } \\
\quad(n=30)\end{array}$} & \multicolumn{2}{|c|}{$\begin{array}{l}\text { High-easy } \\
(n=28)\end{array}$} \\
\hline & $M$ & $S D$ & $M$ & $S D$ & $M$ & $S D$ & $M$ & $S D$ \\
\hline \multicolumn{9}{|l|}{ Trait measure } \\
\hline Prosocial composite $^{a}$ & -0.03 & 2.62 & 0.35 & 3.93 & -0.32 & 3.04 & 0.21 & 2.49 \\
\hline Arousability composite $^{a}$ & 0.30 & 1.77 & 0.27 & 1.56 & -0.29 & 1.79 & -0.16 & 1.66 \\
\hline Social desirability & 1.54 & 0.12 & 1.54 & 0.17 & 1.52 & 0.15 & 1.53 & 0.14 \\
\hline \multicolumn{9}{|l|}{ State measure } \\
\hline Sympathy & 4.59 & 1.43 & 4.58 & 1.51 & 4.87 & 1.54 & 4.57 & 1.31 \\
\hline Personal distress & 3.67 & 1.50 & 3.75 & 1.53 & 3.85 & 1.25 & 3.71 & 1.51 \\
\hline
\end{tabular}

a Scores on these indexes were standardized because the component indexes had different scales.

evocative and the low-evocative, difficult-escape conditions. Of course, such an analysis provides a very stringent test of our hypothesis because it requires a significant difference between conditions in addition to the predicted pattern of correlations.

To match the regression analyses in the previous section, we computed a regression analysis in which variables were entered in blocks. Sex and social desirability were entered first; prosocial composite and condition (an orthogonal contrast comparing the high-evocative, easy-escape condition to the high-evocative and the low-evocative, difficult-escape conditions combined) were entered second; the Sex $\times$ Condition and the Sex $\times$ Prosocial Composite interactions were entered third; the Prosocial Composite $\times$ Condition interaction was entered fourth; and the threeway interaction was entered last. The block of variables containing the prosocial composite was a significant predictor of helping, $r^{2}$ change $=.07$ (over and above the contributions of social desirability and sex), $F(1,99)$ for $r^{2}$ change $=3.73, p<.05$ (multiple $R=.29) ; t\left(\begin{array}{ll}1 & 02\end{array}\right)$ for the prosocial composite $=2.59, p<.01$. The prosocial composite was positively related to helping across all conditions, partial $r(100)=.25, p<.01$. Furthermore, the Prosocial Composite $\times$ Sex $\times$ Condition interaction was a significant predictor of helping, $r^{2}$ change $=.04, F(1,95)$ for $r^{2}$ change $=$ 4.14, $p<.05$ (multiple $R=.37$ ). According to tests of simple effects within sex, the Condition $\times$ Prosocial Composite interaction was significant for women, $r^{2}$ change $=.06, F(1,55)$ for $r^{2}$ change $=4.05, p<.05$ (multiple $R=.38$ ), but not for men. For women, the prosocial composite was positively related to helping within the high-evocative, easy-escape condition, partial $r(14)=$ $.69, p<.03$ (the analogous zero-order $r=.64, p<.01$ ), and unrelated to helping within the combined high-evocative, difficultescape and the low-evocative, difficult-escape conditions, partial $r(27)=-.01, n s$.

Table 4

Partial and Zero-Order Correlations, Controlling for Sex and Social Desirability, Between the Trait and State Measures and Helping in Each of the Evocativeness-Escape Conditions

\begin{tabular}{lcccc}
\hline \multicolumn{1}{c}{ Measure } & Low-difficult & Low-easy & High-difficult & High-easy \\
\hline Trait measure & & & & \\
$\quad$ Prosocial composite & & & & \\
$\quad$ Partial $r$ & .15 & .25 & .18 & $.48^{* *}$ \\
$\quad$ Zero-order & .32 & .38 & .08 & .29 \\
$\quad$ Arousability composite & & & & \\
$\quad$ Partial $r$ & .13 & $.44^{*}$ & -.06 & .15 \\
$\quad$ Zero-order & .16 & $.47^{*}$ & -.04 & -.02 \\
$\quad$ Social desirability & & & & -.34 \\
$\quad$ Partial $r$ & $.50^{* *}$ & .11 & -.33 & -.33 \\
$\quad$ Zero-order & $.50^{* *}$ & .17 & -.36 & \\
State measure & & & & $.48^{* *}$ \\
$\quad$ Sympathy & & .31 & .22 & $.55^{* *}$ \\
$\quad$ Partial $r$ & .13 & .34 & .04 & .23 \\
$\quad$ Zero-order & .07 & .23 & .31 & .34 \\
$\quad \begin{array}{l}\text { Personal distress } \\
\quad \text { Partial } r\end{array}$ & & .25 & .21 & \\
$\quad$ Zero-order $r$ & -.03 & &
\end{tabular}

Note. All correlations were two-tailed. We used the arcsine transformation of helping scores.

a Only sex was partialed in these analyses.

${ }^{*} p<.05 .{ }^{* *} p<.01$. 
To facilitate interpretation of these findings, we computed partial correlations (within each sex controlling for social desirability) between the component indexes of the prosocial composite and helping for the high-evocative, easy-escape condition. For women in the high-evocative, easy-escape condition, trait social responsibility and trait sympathy were positively related to helping, partial $r \mathrm{~s}(14)=.59$ and .61 , both $p \mathrm{~s}<.02$.

To test the hypothesis that the relation between trait altruism and helping would be strongest when the situation was "weak" (Snyder \& Ickes, 1985), an analogous regression analysis was conducted comparing the relation of helping to scores on the prosocial composite in the low-evocative, easy-escape condition (the "weakest" situation) and the high-evocative, difficult-escape condition (the "strongest" situation). As in the previous analysis, the entry of the prosocial composite significantly predicted helping, $r^{2}$ change $=.12$ (over and above the contributions of social desirability and sex), $F(1,99)$ for $r^{2}$ change $=6.82, p<.002$ (multiple $R=.36)$; $t(102)$ for the prosocial composite $=2.90, p<.005$. However, the Condition $\times$ Prosocial Composite interaction was not significant. Thus, the strength of the relation between the prosocial composite and helping did not differ significantly between the weakest and strongest conditions.

Because the prosocial composite was modestly correlated with the emotional arousability composite, $r(102)=.26, p<$ .05 , we also computed the two aforementioned regression analyses for the prosocial composite with one modification-emotional arousability was entered with sex and social desirability in the first block. Entering emotional arousability had little effect on the results of these analyses. Moreover, adding state sympathy to the first block of variables in the first analysis did not diminish the three-way interaction effect (in which the high-evocative, easyescape condition was compared with the two difficult-escape conditions), $F(1,94)=3.74, p<.06$. Thus, state sympathy did not appear to mediate the relation of trait altruism to helping.

In regard to the emotional arousability composite, the main hypothesis to be tested was that of Snyder and Ickes (1985). Thus, we compared the relations of helping with the emotional arousability composite in the weak (i.e., low-evocative, easyescape) and strong (i.e., high-evocative, difficult-escape) conditions. In this regression analysis, sex was entered first; emotional arousability and condition (an orthogonal contrast comparing the weak vs. strong conditions) were entered second; the Sex $\times$ Condition and the Sex $\times$ Emotional Arousability interactions were entered third; the Emotional Arousability $\times$ Condition interaction was entered fourth; and the three-way interaction was entered last. The block containing condition was a significant predictor of helping, $r^{2}$ change $=.05, F(1,102)$ for $r^{2}$ change $=2.99, p<.05$ (multiple $R=.26$ ); $t(104)$ for condition $=$ $2.42, p<.02$. Furthermore, the Emotional Arousability $\times$ Condition interaction was a marginally significant predictor of helping, $r^{2}$ change $=.03, F(1,99)$ for $r^{2}$ change $=3.39, p<.07$ (multiple $R=.31$ ). Consistent with Snyder and Ickes's (1985) theorizing, the arousability composite was positively related to helping in the low-evocative, easy-escape condition but nonsignificantly related to helping in the high-evocative, difficult-escape condition (see Table 4).

To examine which aspect of the arousability composite primarily accounted for the aforementioned significant result, we correlated the component indexes of the composite (controlling for sex) with helping in the low-evocative, easy-escape condition. In the weak condition, trait affective intensity (Larsen's scale) scores were positively associated with helping, partial $r(21)=$ $.46, p<.03$, whereas trait personal distress (Davis's scale) was unrelated to helping, partial $r(21)=.17, n s$. In addition, it is interesting to note that in this condition, the arousability composite scores were associated with scores for the prosocial composite, partial $r(21)=.47, p<.03$, and state personal distress, partial $r(21)=.45, p<.03$, but not for state sympathy, partial $r(21)$ $=.17, n s$. Social desirability was not entered in the initial step of the regression analysis discussed above because there was no significant relation between emotional arousability and social desirability, $r(104)=.07$. However, entering social desirability and sex in the first step of this regression analysis had minimal effect on the results of this analysis. Moreover, entering the prosocial composite in the first step of the regression analysis discussed above had little effect on the pattern of findings. Similarly, controlling for both sex and social desirability had little effect on the correlations regarding emotional arousability.

Because there were no a priori expectations in regard to the relation of social desirability to helping, a regression analysis was computed in which sex was entered first, followed by social desirability and condition; the Sex $\times$ Condition and the Sex $\times$ Social Desirability interactions were entered next, the Social Desirability $\times$ Condition interaction was entered next, and the three-way interaction last. The step at which the Social Desirability $\times$ Condition interaction was entered was significant, $r^{2}$ change $=.09$, $F(1,100)$ for $r^{2}$ change $=10.79, p<.001$ (multiple $R=.37$ ). Social desirability was positively related to helping in the low-evocative, difficult-escape condition (see Table 4) and was not significantly related in any of the other conditions.

\section{Discussion}

The results of the present study provided some support for both predictions stemming from Batson's (1987) work on situational sympathy and for Snyder and Ickes's (1985) distinction between weak and strong psychological situations. With regard to Batson's distinction between easy- and difficult-escape contexts, the finding that the prosocial composite scores were positively correlated with helping in the high-evocative, easy-escape condition (when both sex and social desirability were controlled for) is consistent with Batson's findings in regard to the relation of state sympathy to altruism (although the relation in this study held primarily for women). This pattern of findings supports the notion that there are altruistic individuals who assist primarily for other-oriented or moral reasons without regard to external rewards or punishments. ${ }^{8}$

${ }^{8}$ One could argue that the difference between the present findings and those of Batson et al. (1986) was due to our procedure, which involved less costly helping or more potential for social evaluation. However, subjects helped approximately the same in both studies (across all conditions, $38 \%$ in our study vs. $47 \%$ in Batson et al.'s study), a finding that suggests that the cost of helping was similar across studies. In addition, we used Batson et al.'s procedures to reduce social evaluation concerns, as well as some additional procedures (e.g., subjects were explicitly told that the confederate did not know that they were asked to help). 
In contrast, the pattern of findings did not support the prediction that the relation between indexes of an altruistic personality and helping would be strongest in the high-evocative, easy-escape condition. Perhaps this is because there were sufficient cues of distress in the low-evocative conditions for people high in dispositional sympathy and perspective taking to detect. Indeed, if only subtle cues pertaining to another's distress or need are present, one might expect altruistic individuals to be especially likely to detect and react to those cues.

The gender difference in the relation between the altruistic personality composite and helping in the high-evocative, easyescape condition may be attributed, in part, to a set of values or cognitions specific to women in the helping context. State sympathy was positively related to helping in the high-evocative, easy-escape condition for both men and women, and according to our analyses, state sympathy did not appear to mediate the sex difference in the relations of the trait prosocial composite and helping. However, because the confederate was a woman and the topic (i.e., assaults) might have been more salient and sensitive for women, the situation involving clear cues of distress may have elicited a set of gender-specific values or cognitions related to assisting a needy other who has been assaulted. In other words, cues pertaining to assaults on women may have tapped into women's dispositional other-oriented tendencies and sense of social responsibility as well as elicited sympathy, whereas men's helping may have been determined primarily by their emotional reaction.

Consistent with Snyder and Ickes's (1985) hypothesizing, the arousability composite was positively associated with helping in the low-evocative, easy-escape condition. This pattern of findings was primarily due to the relation of Larsen's Affective Intensity Measure (rather than Davis's personal distress subscale) to helping. Interestingly, scores on the affective intensity scale and the arousability composite index were positively associated with both prosocial composite scores and scores on state personal distress in that condition. Perhaps emotionally reactive people experienced some distress in the low-evocative, easy-escape condition, but not so much that they were unable to tap into their network of prosocial values and cognitions, particularly if this network was salient for the individual. Scores on the arousability composite were not significantly related to scores on state sympathy in this condition; thus, the relation between emotional arousability and helping was not due to emotionally reactive people experiencing more sympathy than less reactive persons in the given situation.

In general, the patterns of relations between indexes of state emotional responding (sympathy and personal distress) and helping were consistent with the most comparable prior research (e.g., Batson, 1987; Schroeder et al., 1988). As expected, feelings of sympathy in the experimental context were positively associated with helping in the high-evocative, easy-escape condition. This relation tended to be higher in the high-evocative, easy-escape condition than in the other three conditions combined. In addition, state personal distress was not significantly associated with helping in any of the four conditions, even though the correlation between state sympathy and state personal distress across the four conditions was significant, $r(107)-.67, p<.01 .^{9}$

The findings concerning the relation of trait social desirability to helping were unexpected and may be unreliable. Further re- search is needed to determine the contexts in which individual differences in social desirability are most likely to influence prosocial behaviors.

In summary, the results of the present study are consistent with existing theory regarding the importance of considering both personality dispositions and contextual demands when predicting social behavior. The association of dispositions to behavior varies across situations, depending on the relevance of the given trait to behavior in the specific context and the psychological pull in that context for the behavior in question or for other modes of response. However, more research is needed to delineate the relevance of various personality characteristics to social behaviors such as helping in different contexts, and the ways in which specific contextual characteristics attenuate or accentuate the relevance of various personality traits for behavior.

\footnotetext{
${ }^{9}$ This high correlation is consistent with previous findings, although in the present study, as in prior studies, state personal distress and state sympathy loaded on different factors in a factor analysis (Batson, 1987).
}

\section{References}

Archer, R. L. (1984). The farmer and the cowman should be friends: An attempt at reconciliation with Batson, Coke, and Pych. Journal of Personality and Social Psychology, 46, 709-711.

Batson, C. D. (1987). Prosocial motivation: Is it every truly altruistic? In L. Berkowitz (Ed.), Advances in experimental social psychology (Vol. 20, pp. 65-122). San Diego, CA: Academic Press.

Batson, C. D., Bolen, M. H., Cross, J. A., \& Neuringer-Benefiel, H. E. (1986). Where is the altruism in the altruistic personality? Journal of Personality and Social Psychology, 50, 212-220.

Berkowitz, L., \& Lutterman, K. G. (1968). The traditional socially responsible personality. Public Opinion Quarterly, 32, 169185.

Cialdini, R. B., Schaller, M., Houlihan, D., Arps, K., Fultz, J., \& Beaman, A. L. (1987). Empathy-based helping: Is it selflessly or selfishly motivated? Journal of Personality and Social Psychology, 52, 729-758.

Cohen, J., \& Cohen, P. (1983). Applied multiple regression/correlation analysis for the behavioral sciences. Hillsdale, NJ: Erlbaum.

Crowne, D. P., \& Marlowe, D. (1964 ). The approval motive. New York: Wiley.

Davis, M. H. (1983). Measuring individual differences in empathy: Evidence for a multidimensional approach. Journal of Personality and Social Psychology, 44, 113-126.

Eisenberg, N. (1986). Altruistic emotion, cognition, and behavior. Hillsdale, NJ: Erlbaum.

Eisenberg, N., Bernzweig, J., \& Fabes, R. A. (in press). Coping and vicarious emotional responding. In T. Field, P. McCabe, \& N. Schneiderman (Eds.), Stress and coping in childhood. Hillsdale, NJ: Erlbaum.

Eisenberg, N., Fabes, R. A., Miller, P. A., Fultz, J., Mathy, R. M., Shell, R., \& Reno, R. (1989). Relation of sympathy and personal distress to prosocial behavior: A multimethod study. Journal 
of Personality and Social Psychology, 57, 55-66.

Eisenberg, N., Fabes, R. A., Schaller, M., Miller, P., Carlo, G., Poulin, R., Shea, C., \& Shell, R. (1991 ). Personality and socialization correlates of vicarious emotional responding. Journal of Personality and Social Psychology, 61, 459-470.

Eisenberg, N., Miller, P. A., Schaller, M., Fabes, R. A., Fultz, J., Shell, R., \&Shea, c. L. (1989). The role of sympathy and altruistic personality traits in helping: A reexamination. Journal of Personality, 57, 41-67.

Fultz, J., Schaller, M., \& Cialdini, R. B. (1988). Three related but distinct vicarious affective responses to another's suffering. Personality and Social Psychology Bulletin, 14, 312-325.

Hoffman, M. L. (1982). Development of prosocial motivation: Empathy and guilt. In N. Eisenberg (Ed.), The development of prosocial behavior (pp. 281-313). San Diego, CA: Academic Press.

Kenny, D. A. (1987). Statistics for the social and behavioral sciences. Boston: Little, Brown.

Larsen, R. J., \& Diener, E. (1987). Affect intensity as an individual difference characteristic: A review. Journal of Research in Personality, 21, 1-39.

Mehrabian, A. (1980). Basic dimensions for a general psychological theory. Cambridge, MA: Oelgeschlager, Gunn, \& Hain.

Romer, D., Gruder, C. L., \& Lizzadro, T. (1986). A person-situation approach to altruistic behavior. Journal of Personality and Social Psychology, 51, 1001-1012.
Rushton, J. P. (1980). Altruism, socialization, and society. Englewood Cliffs, NJ: Prentice-Hall.

Schroeder, D. A., Dovidio, J. E, Sibicky, M. E., Matthews, L. L., \& Allen, J. L. (1988). Empathic concern and helping behavior: Egoism or altruism? Journal of Experimental Social Psychology, 24, 333-353.

Schwartz, S. H. (1968). Words, deeds, and the perception of consequences and responsibility in social situations. Journal of Personality and Social Psychology, 10, 232-242.

Schwartz, S. H., \& Howard, J. A. (1984). Internalized values as motivators of altruism. In E. Staub, D. Bar-Tal, J. Karylowski, \& J. Reykowski (Eds.), The development and maintenance of prosocial behavior: International perspectives on positive development (pp. 229-255). New York: Plenum Press.

Snyder, M., \& Ickes, W (1985). Personality and social behavior. In G. Lindzey \& E. Aronson (Eds.), Handbook of social psychology (3rd ed., pp. 883-948). New York: Random House.

Staub, E. (1974). Helping a distressed person: Social, personality, and situational determinants. In L. Berkowitz (Ed.), Advances in experimental psychology (Vol. 7, pp. 293-341). San Diego, CA: Academic Press.
Submitted May 1990; revised October 1990; accepted January 1991. 